Trinity University

Digital Commons @ Trinity

Health Care Administration Faculty Research

Health Care Administration

9-2005

\title{
Classic or New Monopsony? Searching for Evidence in Nursing Labor Markets
}

Barry T. Hirsch

Trinity University

Edward J. Schumacher

TrinityUniversity, eschumac@trinity.edu

Follow this and additional works at: https://digitalcommons.trinity.edu/hca_faculty

Part of the Medicine and Health Sciences Commons

\section{Repository Citation}

Hirsch, B.T. \& Schumacher, E.J. (2005). Classic or new monopsony? Searching for evidence in nursing labor markets. Journal of Health Economics, 24(5), 969-989. doi: 10.1016/j.jhealeco.2005.03.006

This Article is brought to you for free and open access by the Health Care Administration at Digital Commons @ Trinity. It has been accepted for inclusion in Health Care Administration Faculty Research by an authorized administrator of Digital Commons @ Trinity. For more information, please contact jcostanz@trinity.edu. 


\title{
Classic or new monopsony? Searching for evidence in nursing labor markets
}

\author{
Barry T. Hirsch ${ }^{\mathrm{a}, *}$, Edward J. Schumacher ${ }^{\mathrm{b}, 1}$ \\ a Department of Economics, Trinity University, San Antonio, TX 78212-7200, USA \\ ${ }^{\mathrm{b}}$ Department of Health Care Administration, Department of Economics, Trinity University, \\ San Antonio, TX 78212-7200, USA
}

Received 6 June 2004; received in revised form 11 January 2005; accepted 28 March 2005

Available online 6 July 2005

\begin{abstract}
The market for registered nurses (RNs) is often offered as an example of "classic" monopsony, while a "new" monopsony literature emphasizes that firm labor supply is upward sloping independent of market structure. Using data from multiple sources, we explore the relationship between nursing wages in hospitals and measures of classic and new monopsony. Wage level analysis fails to provide support for classic monopsony, the relative wages of RNs in 240 U.S. labor markets being largely uncorrelated with hospital system concentration. Longitudinal analysis shows nursing wages declining with increases in hospital concentration. We interpret these results as providing support for classic monopsony effects in the short run, but question whether wage effects are sustained in the long run. No relationship is found between nursing wages and a new monopsony measure of mobility, but support for new monopsony is found for women elsewhere in the labor market. RNs display greater interemployer mobility than do women (or men) in general. Two conclusions follow. First, upward sloping labor supply need not imply monopsonistic outcomes. Second, absent more compelling evidence, nursing should not be held up as a prototypical example of monopsony-classic or new.
\end{abstract}

(C) 2005 Elsevier B.V. All rights reserved.

JEL classification: I100-Health economics; J420-Monopsony; J300-Wages; Compensation; Labor costs

Keywords: Monopsony; Wages; Nurses; Hospitals

* Corresponding author at: IZA, Bonn, Germany. Tel.: +1 210999 8112; fax: +1 2109997255.

E-mail addresses: bhirsch@trinity.edu (B.T. Hirsch), eschumac@trinity.edu (E.J. Schumacher).

URL: http://www.trinity.edu/bhirsch, http://www.trinity.edu/eschumac.

1 Tel.: +1 210999 8137; fax: +1 2109998108 .

0167-6296/\$ - see front matter @ 2005 Elsevier B.V. All rights reserved. doi:10.1016/j.jhealeco.2005.03.006 


\section{Introduction}

A common textbook example of monopsony is the market for registered nurses (RNs) employed in hospitals. ${ }^{2}$ The empirical literature, however, provides mixed conclusions. One strand focuses on empirical estimates of RN labor supply elasticities facing hospitals. This research is supportive of monopsony, in general finding upward sloping labor supply curves. A second strand investigates whether relative wage and/or employment outcomes vary with respect to hospital concentration, labor market size, and the like. Such studies provide little support for the classic monopsony model. ${ }^{3}$

These disparate results might be reconciled in several ways. One argument is that monopsony or oligopsony need not produce stable labor market outcomes; these may vary across time and with respect to market conditions. By this argument, one must search across different time periods and labor markets to determine the prevalence of oligopsonistic outcomes. A second argument is that monopsony is widespread, with employers in both concentrated and non-concentrated labor markets facing upward sloping firm-level supply curves owing to imperfect worker mobility (Manning, 2003). Following the argument of the "new monopsony" literature, market structure measures have limited relevance. Employers in large and small markets alike may face upward sloping supply curves and behave as oligopsonistic competitors. A third argument is that upward sloping labor supply is a necessary but not sufficient condition for monopsonistic outcomes (Hirsch and Schumacher, 1995). Although evidence may support existence of upward sloping supply facing individual employers, it need not follow that monopsonistic outcomes result. ${ }^{4}$

This paper addresses these contrasting views in an examination of wage determination in nursing labor markets. We provide tests of "classic" and "new" monopsony. The search for classic monopsony first examines whether relative wages of hospital RNs in urban markets is related to hospital system concentration and market size, the latter approximating the number of non-nursing and non-hospital nursing employers. We next examine whether changes in hospital concentration across markets lead to changes in relative RN wages, suggesting that this relationship represents a short-run but not necessarily long-run outcome.

The search for new monopsony relies on a simple measure of oligopsonistic power proposed by Manning (2003) — the proportion of new hires from outside employment. If the proportion of new hires from employment (i.e., from other jobs) is high, the suggestion is that workers are mobile (an elastic firm-level labor supply) and monopsonistic power

\footnotetext{
${ }^{2}$ Five leading undergraduate labor economics texts were examined. Four identify hospital RNs as an example of monopsony. Two of these four, note that evidence for monopsony is mixed. The other two provide no such qualification. A recent paper on nursing monopsony states: "Thus, if one found no evidence of monopsony in this market, it would be difficult to argue that monopsonistic competition was a pervasive feature of the labor market" (Staiger et al., 1999, p. 2). Boal and Ransom (1997) provide a comprehensive survey of the monopsony literature.

3 Examples of the first strand are Sullivan (1989) and Staiger et al. (1999) and of the second Adamache and Sloan (1982) and Hirsch and Schumacher (1995). Sullivan (1989), generally cited as finding evidence of monopsony, also can be included with the latter group since he fails to find area wage differences associated with market structure.

${ }^{4}$ An additional argument is that labor supply studies finding a positive inverse elasticity fail to measure long-run supply. Despite the difficulty in estimating firm-level labor supply curves, we do not challenge the conclusion that hospitals (among other firms) face upward sloping labor supply curves over a lengthy planning horizon.
} 
is weak. If new hires come primarily from outside employment (unemployment or out of the labor force), there may exist little mobility across employers. We calculate job transition rates for hospital RNs and a control group of female workers across urban labor markets.

\section{Classic monopsony and structural changes in health care labor markets}

Most RNs are employed in hospitals. It is the dominant role of hospitals in the RN labor market that has made nursing a common example of monopsony. The effect of hospitals on nursing wages and employment, however, need not be invariant over time. Two changes in recent years may have affected hospital market power. First, the share of total RN employment within hospitals has declined. Second, merger activity has led to consolidation within the hospital industry. The former trend should weaken and the latter strengthen hospitals' oligopsonistic power.

Information on occupation and industry in the Current Population Survey (CPS) permits us to identify RNs and their sector of employment. Based on compilations from the CPS, $73 \%$ of the 1.42 million RNs employed in the U.S. in 1985 were employed in hospitals. RN employment had risen to 2.24 million by 2002, but the share employed in hospitals had fallen to $62 \%$. Much of the movement of RN employment out of hospitals occurred during the mid1990s following structural changes in the industry. RNs increasingly can seek employment in physician-owned specialty facilities, where outpatient procedures once conducted in hospitals are now performed. Jobs in these facilities typically have Monday-Friday daytime work schedules without overtime or on-call duty. The movement of health personnel out of hospitals is not unique to RNs. During the same 1985-2002 period, the percentage of licensed practical nurses (LPNs) employed in hospitals fell from 57 to 28\%; the percentage of nursing aides fell from 31 to $23 \%$. $^{5}$

The financial environment and market structure of the health care industry has been in continuous change since the mid-1980s. Important have been the rise of managed care and hospital consolidation (Gaynor and Hass-Wilson, 1999). The early 1990s was a period in which managed care and the use of cost containment strategies expanded, placing downward pressure on growth rates in health care expenditures and on labor costs. Hospital mergers began increasing during the early 1990s. The peak year was 1996, with 235 hospital mergers involving 768 facilities, with $15 \%$ of all hospitals being involved in a merger that year. Following this consolidation, merger activity slowed during the late 1990s and early 2000s. In 2003, for example, there were 68 mergers involving 100 facilities. Figures for 2004 suggest a pick up in activity, with 84 mergers involving 170 facilities (Modern Healthcare Staff Reports, January 11, 1999 and January 24, 2005). Consolidation has generated attention from industry analysts regarding its effect on output markets (Lynk, 1995; Melnick et al., 1999; Dranove and Ludwick, 1999; Gaynor and Vogt, 2003; Cuellar and Gertler, 2004),

\footnotetext{
5 These figures are calculated from CPS monthly earnings files using employment weights. Schumacher (1997, Table 1) provides annual hospital and nonhospital employment for RNs and LPNs beginning in 1977. In 1977, $72 \%$ of RNs and $63 \%$ of LPNs were employed in hospitals. Buerhaus et al. (2004) describe recent RN employment changes in the CPS.
} 
health care costs (Fong, 2003), and its implications for antitrust policy (Taylor, 2003). ${ }^{6}$ There is little research, however, on the effects of hospital market structure on labor markets. Our focus is its effect on the labor market for hospital RNs.

\section{New views on monopsony: examining mobility in nursing labor markets}

The new monopsony/oligopsony literature (Bhaskar et al., 2002; Manning, 2003) emphasizes the widespread presence of monopsonistic power. Because of imperfect information, firm-specific training, worker-specific attachment to firms, and immobility arising from various sources, employers face upward sloping labor supply. Profit maximizing wages and employment, it is argued, should vary with respect to the labor supply elasticity. A familiar characterization is that the proportional gap between the marginal revenue product and wage is equal to the inverse of the labor supply elasticity, or $(Y-w) / w=\varepsilon$, where $Y$ is the marginal revenue product, $w$ the wage, and $\varepsilon$ the inverse elasticity. The competitive case of infinitely elastic labor supply $(\varepsilon=0)$ implies zero exploitation; that is, no markdown of labor's wage relative to its marginal revenue product. The new monopsony model requires only that firms' labor supply curves be upward sloping. The slope need not be highly correlated with measures of employer concentration and market size.

Manning proposes a simple measure to approximate monopsonistic power, measured by the share of new employees ("recruits") that move from other employers rather than from unemployment or out of the labor force. ${ }^{7}$ The intuition is that it is the ability and willingness of workers to move between employers that most constrains monopsonistic power. The lower the proportion of new hires coming from employment with other firms, the lower are expected wages and employment, all else the same. Letting $R$ be the number of newly hired workers (recruits) in a given market, each of whom arrives from one of three states- $e$ being employment elsewhere, $u$ being unemployment, or $n$ being outside the labor force. The measure of monopsony power, $M$, the fraction of new recruits from non-employment, is:

$$
M=\frac{(u+n)}{R}=1-\left(\frac{e}{R}\right) .
$$

Manning shows that this "back of the envelope" measure is a good proxy for monopsony power (an inverse measure of competition) in many labor market models, and is necessarily a monotonic function of a measure derived in the Burdett and Mortenson (1998) model of equilibrium wage differentials. ${ }^{8}$

\footnotetext{
${ }^{6}$ Since the late-1990s, health care costs have risen sharply. Per-capita health expenditures increased by $7.7 \%$ in 2003 to U.S.\$5670 per capita, accounting for $15.3 \%$ of GDP, an increase from $13.3 \%$ in 2000 following stability through much of the 1990s (Smith et al., 2005).

7 Ideally, one would estimate the elasticity of firm-level labor supply curves, but this is difficult given a paucity of firm data and difficulty identifying employment effects associated with exogenous wage change (see Staiger et al., 1999).

${ }^{8}$ Although $M$ provides a direct measure of inter-employer mobility, we do not argue that it is a perfect proxy for the inverse elasticity or monopsony. As pointed out by a referee, one would like to account for differences in firm turnover that are independent of mobility reflected in the supply elasticity.
} 
Manning estimates values of $M$ for the U.S. and U.K. labor forces. The U.S. measures are compiled from the 1994-2000 monthly Current Population Surveys, utilizing the rolling panel nature of the CPS. Manning obtains an estimate of $M=.55$, with values of .59 for women and .50 for men (Manning, 2003, Table 2.2). He states that differences in $M$ across types of workers mirror wage differences, basing this conclusion on regression correlates of transition probabilities - female, black, and poorly educated new hires having higher probabilities of a transition from non-employment than from employment. ${ }^{9}$

The literature on monopsony (classic and new) implicitly assumes that a finding of upward sloping labor supply is sufficient evidence for the exercise of monopsonistic power. Manning (2003), for example, points to two unpublished studies providing what appear to be good instruments to identify firm-level labor supply. He cites each of these as providing strong evidence for the existence of monopsonistic power (in the markets on which these studies are based) and as examples of the type of work of which more is needed.

We accept the premise that there is substantial heterogeneity and wage variability across firms (Mortensen, 2003) and that most employers face upward sloping labor supply over a short- and perhaps long-run horizon. We do not accept the premise that upward sloping supply necessarily implies wages that vary with the inverse elasticity. Wages paid to workers affect such things as retention, applicant queues, search costs and strategies, unmeasured worker quality, and worker effort. "Imperfect" worker mobility may reflect factors such as implicit incentive contracts, specific training, and worker rents, most often associated with higher rather than lower wages. Non-zero inverse labor supply elasticities should not be regarded as sufficient evidence that employers possess and are exercising employer power with respect to wages. ${ }^{10}$

If wages need not vary with measured labor supply elasticities, it is essential to look at the evidence. Below we examine whether wages vary systematically with measures such as $M$ that, according to the new monopsony literature, reflect cross-market differences in labor supply elasticities and monopsonistic power.

\section{Method of analysis and data}

\subsection{Method of analysis}

In order to examine how market structure and labor mobility affect nursing wages, we measure the wages of hospital RNs relative to a comparison group within the same labor markets. This approach controls not only for differences in measurable worker characteristics, but also for cost-of-living differences, area-specific amenities and disamenities, unmeasured labor quality specific to an area, and other market-specific wage determinants (e.g., demand shocks) that otherwise are not readily measured.

\footnotetext{
${ }^{9}$ An exception is Hispanic new hires, who are less likely to have come from non-employment.

10 The arguments in this paragraph apply to classic as well as new monopsony. There exist multiple employers of RNs even in small markets, making wage outcomes indeterminate. A priori, we do not know how many employers are required to produce relatively competitive wage outcomes.
} 
The analysis adopts a two-step estimation procedure, based on Hirsch and Schumacher (1995), in which labor markets are the second-step unit of analysis. Similar results (not shown) are obtained using a single-step procedure with individuals as the observation unit (Hirsch and Schumacher, 2004a). In the first-step, we estimate micro wage equations from which we obtain area-specific RN wage differentials for each MSA/CMSA and non-urban state group. These differentials represent the difference between nursing and non-nursing wages, conditioned on measurable characteristics that vary across individuals within markets.

A second-step equation relates $\mathrm{RN}$ wage differentials to measures of classic and new monopsony. The nursing/non-nursing area differentials $(n=240)$ estimated in the first-step are regressed on market characteristics that vary across but not within areas, including market size, hospital concentration, and the new monopsony measure $M$. The classic monopsony model predicts that relative nursing wages are lower in less competitive markets, increasing with respect to hospital (employer) concentration and market size (proxying non-hospital and non-nursing employment opportunities). The new monopsony model predicts that relative nursing wages decrease with respect to $M$, higher values of $M$ reflecting less elastic firm-level labor supply curves. The second-step equation is estimated by weighted least squares (WLS) and includes the means of first-step variables, reducing the likelihood of spurious correlation (Baker and Fortin, 2001). ${ }^{11}$

More formally, first-step wage equations, including RN and control group workers, take the form:

$$
\ln W_{i t k}=\alpha+\Sigma \beta_{j} X_{j i t k}+\Sigma \gamma_{k} \mathrm{AREA}_{k i t}+\Sigma \varphi_{k} \mathrm{RN} \cdot \mathrm{AREA}_{k i t}+e_{i t k},
$$

where $\ln W_{i t k}$ is the natural $\log$ of hourly earnings of worker $i$ in time period $t$ in labor market $k$ (where $k=1, \ldots, 240$ ), $\alpha$ is the control group intercept for area $k=1$ and period $t=1, \mathrm{RN}$ is a dummy variable equal to 1 for RNs, $X$ includes individual-level variables (indexed by $j$ ) affecting nursing and control group wages with $\beta_{j}$ the attaching coefficients, and $e_{i t k}$ is the error term. AREA is a set of dummies corresponding to the 191 CMSA/MSAs and 49 non-urban state areas, with $\gamma_{k}(k=2, \ldots, 240)$ representing the area wage differentials for the control group relative to the omitted reference area, and $\varphi_{k}(k=1, \ldots, 240)$ measuring the 240 area-specific wage differentials for RNs relative to the control group. There is no separate nursing dummy since $\mathrm{RN}$ is interacted with all 240 markets. Included in $X$ are years of potential experience and its square, the state unemployment rate in year $t$, and dummies for schooling degree (3), marital status (2), race/ethnicity (3), gender, part-time, union membership, public-sector status, region (8), and year (4).

A second-step WLS regression can then be estimated with the area-specific nursing wage differentials $\varphi_{k}$ as the dependent variable $(n=240)$. We estimate:

$$
\varphi_{k}=\Phi+\theta \mathrm{HI}_{k}+\Sigma \psi_{s} \mathrm{SIZE}_{s k}+\zeta M_{k}+\Sigma \beta^{\prime} X_{k}^{\prime}+v_{k} .
$$

Here, $\varphi_{k}$ is the nursing differential for area $k$ estimated in the first-step regression, $\Phi$ the intercept, HI the Herfindahl index and $\theta$ its coefficient, SIZE $_{s k}$ the dummy variables rep-

\footnotetext{
${ }^{11}$ Saxonhouse (1976) shows that when using regression parameters as a dependent variable, each observation should be weighted by the inverse of that parameter's standard error. Qualitative results are similar using $n$ or $\sqrt{ } n$ as weights.
} 
resenting seven metropolitan area size groups (indexed by $s$; non-urban state areas are the reference group) and $\psi_{s}$ the corresponding coefficients, $M$ the proportion of new recruits from outside employment with $\zeta$ its coefficient, and $v_{k}$ is a random error term. $X^{\prime}$ represents the city-specific means of the individual $X^{\prime}$ s from the first-step equation and $\beta^{\prime}$ is the set of coefficients. The expectation from classic monopsony is that $\theta$ will be negative and $\psi_{s}$ positive and increasing with market size. The expectation from new monopsony is that $\zeta$ will be negative.

Wage level equations such as (3) rely on cross-section differences to identify the long-run impact of market structure on wages. Data for two periods permit us to estimate the wage equation in difference form, with changes in relative $\mathrm{RN} /$ control group wages a function of changes in market structure. We estimate:

$$
\Delta \varphi_{k}=\Phi^{\prime}+\Sigma \beta^{\prime} \Delta X_{k}^{\prime}+\theta^{\prime} \Delta \mathrm{HI}_{k}+\Sigma \psi_{s}^{\prime} \mathrm{SIZE}_{s k}+v_{k}^{\prime},
$$

where $\Delta$ is the difference operator between time periods and $\theta^{\prime}$ provides an estimate of the response of nursing wages to changes in hospital concentration. Because changes in relative market size (population) are minimal, $\triangle \mathrm{SIZE}$ is not included. We include $\mathrm{SIZE}_{s}$, allowing wage changes to vary with market size. We are also unable to control for $\Delta M$, given the small samples used to compute $M$ by area ( $M$ is included in (4)).

Wage change or longitudinal analysis provides a direct measure of short-run effects; that is, we observe short to medium-run responses of nursing wages to changes in hospital market structure. Such analysis is often used to account for unmeasured fixed effects that may bias cross-sectional estimates of the long-run effects. In this application, however, we cannot identify fixed effects that are likely to be important-specifically, omitted determinants of RN wages that are highly correlated with hospital concentration and weakly correlated with other included variables. Thus, our preference is to interpret the wage level results as providing reasonable long-run estimates and the wage change results as providing short-run estimates. Under the plausible assumption that wages adjust more quickly than long-run labor supply (which requires time to acquire RN training and to move across cities), short-run wage differences may be large compared to long-run differences. For example, the wage effects of merger demand shocks may be moderated over time. $^{12}$

The analysis assumes that unmeasured differences across markets in cost of living, labor quality, working conditions, and area amenities affect nurses and the control group in similar fashion. Such an assumption appears reasonable since the control group selected provides an opportunity cost measure of the long-run alternatives available to nursing personnel, and cost of living and area amenities should be similar for nurses and the control group. The conditional control group wage need not provide a perfect measure of the relative wage; rather, our methodology is appropriate as long as measurement errors in the relative wage are not systematically correlated with market size, hospital concentration, or $M .^{13}$

\footnotetext{
12 Readers who remain concerned about omitted fixed effects may want to place less weight than do we on the wage level results and interpret the longitudinal results as long-run estimates.

13 An additional concern is correlation between unmeasured labor quality and area size (Hirsch and Schumacher, 2004a).
} 


\subsection{Data}

We use four data sources. The primary data for this study are drawn from the monthly CPS Outgoing Rotation Group (ORG) earnings files for January 1993 through December 2002. Data and analysis are divided into two periods, 1993-1997 and 1998-2002. For the sake of brevity, results reported are for the latter period (for complete results, see Hirsch and Schumacher, 2004a). The CPS provides reasonably large samples of RNs and very large samples of health care and non-health workers from which appropriate control groups can be constructed.

Workers in the CPS are assigned to one of 240 "markets" comprising 191 metropolitan statistical areas or consolidated metropolitan statistical areas (MSA/CMSA) and 49 state groups that include all workers within a state not living in an MSA/CMSA. ${ }^{14}$ Thus, we have representative national samples with all workers assigned to a market. Unlike the metropolitan areas, the non-urban state groups may not form unified labor markets, suggesting caution in interpreting results specific to these areas (we show results with and without the non-urban state groups).

The CPS nursing sample includes all hospital registered nurses (RNs). The control group for RNs is area-specific and includes women (92\% of RNs are women in the 1998-2002 CPS sample) with either an associate or baccalaureate degree, employed in non-health related occupations within the following broad occupational categories: executive, administrative, and managerial; professional specialty; technicians and related support; sales; administrative support and clerical; service (except protective and household services). Excluded are all health-related workers since hospital behavior and wage policies can affect their earnings. Principal results are not sensitive to the choice of control group workers.

The RN and control group samples include employed wage and salary workers ages 18 and over, with positive weekly earnings and hours. The wage on the primary job is measured directly for workers reporting hourly earnings and who do not receive tips, commissions, or overtime. For others, the wage is calculated by dividing usual weekly earnings on the primary job (including tips, commissions, and overtime) by usual hours worked per week. ${ }^{15}$ Usual weekly earnings are top-coded at U.S.\$ 1923 through 1997 and at U.S.\$ 2885 beginning in 1998. Those at the cap are assigned mean earnings above the cap based on year and genderspecific estimates that assume a Pareto distribution for earnings beyond the median. ${ }^{16} \mathrm{We}$ omit the few workers with measured hourly earnings less than U.S.\$3 or greater than U.S.\$ 150 (in 2002 dollars).

Workers who have had their earnings, occupation, or industry imputed by the Census are also excluded. Few workers have occupation or industry imputed. A large number (about $30 \%$ in recent years) have earnings imputed by the Census based on a cell hot-deck procedure

\footnotetext{
14 There are 173 MSAs, 18 CMSAs and 49 non-urban state groups (all of New Jersey and D.C. are in MSA/CMSAs). CMSAs contain two or more primary metropolitan statistical areas (PMSAs). Further detail is provided in our working paper (Hirsch and Schumacher, 2004a).

15 If necessary, those reporting "variable" hours have their implicit wage calculated using hours worked last week.

16 Estimates of gender-specific means above the cap for years since 1973 are posted at www.unionstats.com. Values are about 1.5 times the cap, with somewhat smaller female than male means and modest growth over time.
} 
in which non-respondents are assigned the earnings of a "donor" with an identical set of match characteristics. It is important that imputed earners be excluded owing to "match bias" (Hirsch and Schumacher, 2004b). First, since non-responding hospital RNs are not in general matched to the earnings of other hospital RNs (industry is not a match criterion and occupation is defined at a broad level), wage differences between RNs and the control group are biased toward zero. Second, location is not a donor match criterion in the ORGs, causing wage differences across areas to be artificially compressed. Following the above sample restrictions, the CPS sample sizes of hospital RNs and the college-educated female control group are 7982 and 63,464 for the 1993-1997 period and 6732 and 61,391 during 1998-2002.

A second data source is the Annual Survey of Hospitals conducted by the American Hospital Association. Data for individual hospitals are available on such things as location, employment, average daily census, number of beds, and hospital system name. The AHA survey is used to calculate Herfindahl indices of hospital concentration by market area, corresponding to the metropolitan, and non-metropolitan areas identified in both the CPS and AHA survey. ${ }^{17}$ The Herfindahl index, $\mathrm{HI}$, is defined as $\mathrm{HI}_{k}=\Sigma_{k} s_{i}{ }^{2}$, where $k$ indexes the market area and $s_{i}$ is the proportional market share of each hospital (or hospital system) in an area. $\mathrm{HI}$ is bounded $[0,1]$ with low values representing a high degree of product and labor market competition and 1 representing a single hospital (or system) in the market. HI indices are compiled using the hospital "average daily census" as the output measure (equivalent results are obtained using "number of beds") and, alternatively, with individual hospitals or hospital systems as the observation unit (in the latter, all area hospitals part of the same system are counted as a single hospital). ${ }^{18}$ Hospital information for 1993 is matched to our 1993-1997 CPS sample and information for 2000 to the 1998-2002 CPS sample (we were unable to calculate system-based concentration using the 1995 AHA survey).

A third data source is the full CPS (all rotation groups) for 1994-2002. As described in Appendix A, these data are used to measure the proportion of new recruits hired from outside the labor force, from unemployment, and from employment elsewhere, allowing us to estimate RN and control group new monopsony measures $M^{\mathrm{RN}}$ and $M^{\mathrm{C}}$ in a manner similar to Manning (2003). Unfortunately, there are only 645 hospital $\mathrm{RN}$ recruits in the 1994-2002 CPS. This sample provides useful information on national mobility patterns for hospital RNs as compared to other groups of workers, but does not permit us to construct a reliable measure of $M^{\mathrm{RN}}$ across our 240 labor markets.

We use a fourth data set, the National Sample Survey of Registered Nurses (SRN), to measure $M^{\mathrm{RN}}$ by CMSA/MSA. The SRN is a voluntary survey of roughly 30,000 licensed

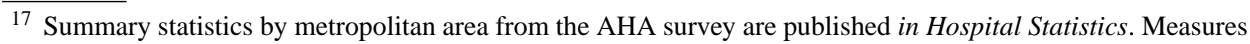
include number of hospitals, RN employment, compensation costs, expenditures, patient days, and costs per patient. These data were used in Hirsch and Schumacher (1995) to construct a hospital density measure (hospitals per square mile).

18 We chose an output measure (census) rather than employment to calculate hospital concentration, since employment is a monopsonistic outcome we later examine. The AHA survey designates an MSA/PMSA location and state. In order to get an exact match for CMSAs designated in the CPS, the hospital data were aggregated from the component PMSAs. Data from small MSAs not designated in the CPS were combined with data from the non-metro portions of states to calculate values for the 49 non-urban CPS state areas. We thank Joanne Spetz and Wendy Dyer for their substantial assistance in accessing the AHA data and calculating the Herfindahl indices.
} 
RNs. The 1984, 1988, 1996, and 2000 (but not 1992) surveys ask RNs whether they were employed as an RN on the same date 1-year ago and, for those who answer yes, whether their current employer is the same as 1-year ago. Using this information, we construct measures of $M^{\mathrm{RN}}$ by labor market based on a much larger sample size of hospital RNs than in the CPS. Recruits are defined as all current hospital RNs, minus those who were employed as an $\mathrm{RN}$ and have the same employer as a year ago. $M^{\mathrm{RN}}$ is equal to $1-e / R$, where $R$ represents recruits (defined above) and $e$ is the number of RNs employed 1-year ago as an RN but with a different employer.

Unlike the CPS, the SRN measure of $M^{\mathrm{RN}}$ retains individuals who have moved or changed households and uses a 1-year rather than 1-month time frame. In addition, the "inside" group $e$ moving from employment in the SRN includes only those from another RN job, with the "outside" group $u+n$ consisting not only of those unemployed and not in the labor force, but also those moving from non-RN occupations. These differences are advantageous. First, the SRN retains RN recruits who have moved in conjunction with their new job. Second, the labor supply elasticity facing hospitals might better be proxied by transitions between $\mathrm{RN}$ jobs absent transitions from non-RN to RN jobs. Third, transitions between $\mathrm{RN}$ jobs sometimes include brief voluntary breaks in employment. Using the CPS monthly time frame, these latter job transitions are measured as movements from unemployment or out of the labor force. Brief breaks in employment are bypassed in the SRN, counted instead as cross-employer transitions and not movements from unemployment or outside the labor force. The SRN does have limitations. Sample sizes in many markets are not large, so measurement error remains a concern. ${ }^{19}$

\section{Evidence}

\subsection{Descriptive results}

Table 1 provides means for the hospital RN sample nationwide and for selected market sizes for the 1993-1997 and 1998-2002 periods. ${ }^{20}$ In the latter period, the (unconditioned) relative nursing wage is 1.38 , a $38 \%$ wage advantage compared to the college-educated female control group. Relative RN wages, if anything, decrease with market size, inconsistent with classic monopsony but similar to results for 1993-1997 and for an earlier period (Hirsch and Schumacher, 1995). Herfindahl indices of hospital concentration (HI and S-HI) decrease sharply with market size, and increase markedly between 1993 and 2000. The number of hospitals fell by about 10 between the two periods, declining in every city size category. The mean number of hospital systems decreased by 14, reflecting nationwide consolidation. Hospitals per square mile increase with market size, but declined between 1993 and 2000, most notably in larger markets.

\footnotetext{
${ }^{19}$ Smaller markets, however, generally receive a lower weight in the WLS analysis. Response to the SRN is voluntary. SRN sample weights, designed to account for the probability of survey non-response, are used to calculate $M^{\mathrm{RN}}$.

${ }^{20}$ Table 1 means are compiled across the CPS sample of RNs. This is equivalent to compiling weighted means across markets, with the RN sample sizes as weights. All city size categories are shown in Hirsch and Schumacher (2004a).
} 
Table 1

Mean nursing and hospital characteristics by selected metropolitan area size

\begin{tabular}{llllll}
\hline & All & Non-urban state & $100-200 \mathrm{~K}$ & $500 \mathrm{~K}-1 \mathrm{M}$ & $5 \mathrm{M}+$ \\
\hline 1998-2002 & & & & & \\
Wage, Hosp RNs (2002 U.S.\$) & 23.24 & 20.79 & 21.85 & 22.55 & 26.54 \\
RN/control wage ratio & 1.38 & 1.56 & 1.52 & 1.45 & 1.29 \\
\# Hospitals & 49.10 & 57.92 & 3.19 & 10.23 & 108.93 \\
\# Hospital systems & 31.88 & 42.54 & 2.77 & 8.13 & 64.97 \\
Hosp/100 Sq miles & .54 & .14 & .31 & .55 & 1.08 \\
Hosp/100K Pop & 1.72 & 3.04 & 1.98 & 1.40 & .97 \\
HI (Herfindahl index) & .123 & .068 & .553 & .168 & .019 \\
System-HI & .169 & .092 & .605 & .219 & .052 \\
1993-1997 & & & & 21.13 & 25.19 \\
Wage, Hosp RNs (2002 U.S.\$) & 22.31 & 20.16 & 1.71 & 1.44 & 1.36 \\
RN/control wage ratio & 1.43 & 1.54 & 3.67 & 10.90 & 125.28 \\
\# Hospitals & 58.81 & 59.36 & 3.47 & 9.58 & 98.52 \\
\# Hospital systems & 46.05 & 46.15 & .39 & .58 & 1.30 \\
Hosp/100 Sq miles & .66 & .16 & 2.33 & 1.52 & 1.13 \\
Hosp/100K Pop & 1.75 & 2.78 & .457 & .150 & .016 \\
HI (Herfindahl index) & .098 & .062 & .489 & .170 & .030 \\
System-HI & .118 & .082 & 33 & 32 & 9 \\
\#MSA/CMSAs [state groups] & 240 & {$[49]$} & & \\
\hline RN and contrl grap & & & & \\
\hline
\end{tabular}

RN and control group wage data are from the 1993-2002 CPS ORG earnings files. Hospital data are from the AHA Annual Survey of Hospitals for the years 1993 and 2000 (American Hospital Association, 1994, 2002). All means are compiled across the CPS sample of hospital RNs (equivalent to the weighted mean across markets, with RN sample sizes as weights). The 191 metropolitan areas shown apply strictly to the latter period and the portion of the 1993-1997 sample after September 1995. For details and means for all city size categories, see Hirsch and Schumacher (2004a). The 49 non-urban state areas include all workers not residing in one of the designated metropolitan areas. The Herfindahl index, HI, is calculated using the average daily census and based, alternatively, on individual hospital and system market shares, the latter counting as a single entity all hospitals within a system in a market area.

Fig. 1 provides a complete representation of the relationship between the estimated $\mathrm{RN} /$ control wage $\varphi_{k}$ and market size (log of population) during 1998-2002. We normalize the relative wage at zero, the value shown on the vertical axis being each market's relative wage minus the unweighted mean across all 240 markets. Relatively small samples of RNs lead to higher dispersion across small than large markets. Absent covariates, no positive relationship exists between relative nursing wages and market size. Observations are clustered between -.20 and .20 , with a slight negative relationship between relative RN wages and size. The principal route through which classic monopsony is thought to impact nursing wages is through the market power of hospitals. Fig. 2 shows the relationship between the normalized RN/Control group wage differentials and the system HI in each market. The relationship is flat, indicating no support (absent covariates) for the negative relationship predicted by classic monopsony theory.

Descriptive data on the new monopsony measures are provided in Table 2 . Since $M$ varies little with respect to market size, only nationwide measures are shown. The mean of $M^{\mathrm{RN}-\mathrm{CPS}}$ is .418 , indicating that $58 \%$ of hospital $\mathrm{RN}$ recruits come from employment elsewhere, with $42 \%$ coming from outside the labor market (for non-hospital RNs, $M=.436$ ). Among those 


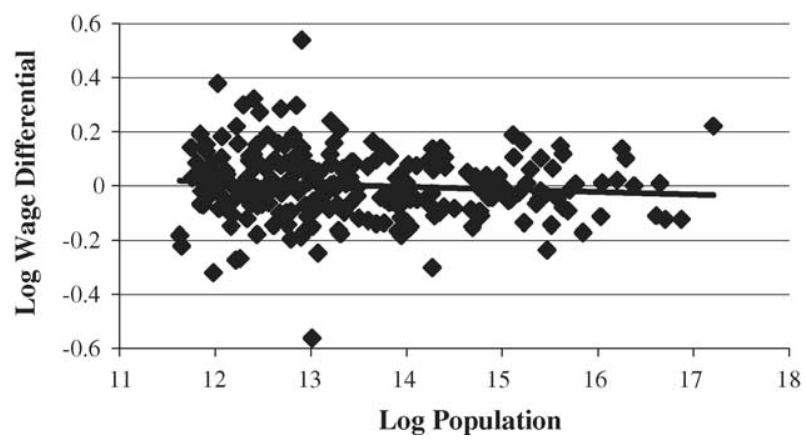

Fig. 1. 1998-2002 RN/control wage differentials by market size. Shown are RN/control group 1998-2002 log wage differentials for 240 labor market areas (191 MSA/CMSAs and 49 non-urban state groups), estimated from step one of the two-step procedure described in the text. Relative wage differentials are normalized at zero, the value shown on the vertical axis being each market's relative wage minus the unweighted mean across all markets.

coming from outside employment, . 137 were from $u$ and .281 from $n$ in the prior month. Among those .582 from employment, .349 have moved from an RN hospital job, .082 from an RN job outside a hospital, and .151 from a non-RN occupation (these figures are not shown in Table 2). $M^{\mathrm{RN}-\mathrm{SRN}}$ has a mean of .326 , indicating that $67 \%$ of hospital RNs recruits in the SRN were employed elsewhere as an RN 1-year ago (we know nothing more about their prior job). The lower value of $M^{\mathrm{RN}-\mathrm{SRN}}$ than of $M^{\mathrm{RN}-\mathrm{CPS}}$ arises from the 1-year time frame in the SRN as compared to 1 month in the CPS, allowing nurses who take a short time off between nursing jobs to be counted as moving from employment rather than nonemployment. Working in the opposite direction, the non-employment category in the SRN includes RNs previously employed as non-RNs. We use $M^{\mathrm{RN}-\mathrm{SRN}}$ to measure cross-market differences owing to its larger sample of recruits (7834 versus 645) and the preferable 1year time frame. $M^{\mathrm{RN}-\mathrm{CPS}}$ at the national level is useful because one can identify (as above) features of the prior as well as current job and because it can be compared to CPS values of $M$ calculated for alternative worker groups.

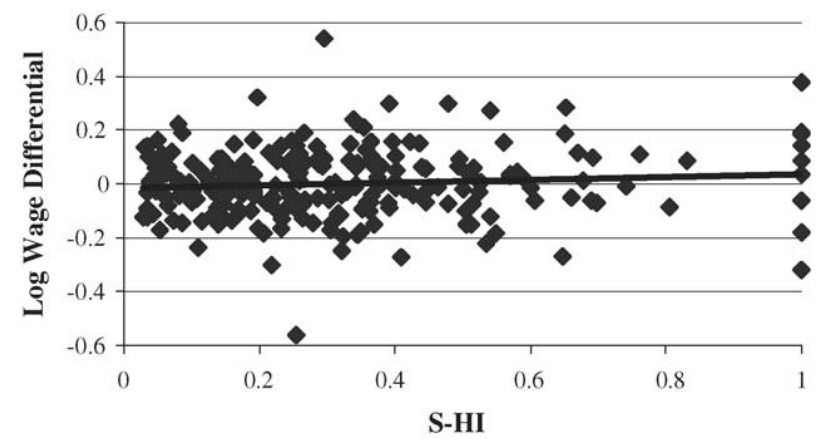

Fig. 2. 1998-2002 RN/control wage differentials by system Herfindahl index. Shown on the vertical axis are normalized 1998-2002 RN/control group log wage differentials for 240 market areas (see Fig. 1 note). Shown on the horizontal axis is the hospital system Herfindahl concentration index in 2000. 
Table 2

New monopsony measure means by worker group

\begin{tabular}{lr}
\hline Hospital registered nurses & \\
SRN measure $M^{\text {RN-SRN }}$ & .326 \\
CPS measure $M^{\text {RN-CPS }}$ & .418 \\
Female control group & .512 \\
$M^{\mathrm{C}}$ & \\
Women & .581 \\
All & .640 \\
Low education & .528 \\
High education & \\
Men & .466 \\
All & .523 \\
Low education & .399 \\
High education & \\
\hline
\end{tabular}

With the exception of $M^{\mathrm{RN}-S R N}$ the new monopsony measures are compiled from the 1994-2002 CPS. $M$ measures the proportion of new hires from outside employment, a proxy for the inverse supply elasticity. The SRN measure of $M$ is compiled from the National Sample Survey of Registered Nurses (SRN) for 1984, 1988, 1996, and 2000. Low education includes all workers with a high school degree or less; high education includes all with a degree beyond high school. See the text and Appendix A for further discussion.

The new monopsony literature emphasizes that positively sloped labor supply exists independent of employer concentration. Neither $M^{\mathrm{RN}-\mathrm{SRN}}$ nor $M^{\mathrm{C}}$ is found to vary with market size. Likewise, $M^{\mathrm{RN}-\mathrm{SRN}}$ and hospital concentration (S-HI) are not highly correlated across markets ( $\rho$ is -.06 , with RN sample sizes as weights), thus permitting a clean statistical delineation between the effects of classic and new monopsony.

An important finding is that $M^{\mathrm{RN}-\mathrm{CPS}}<M^{\mathrm{C}}(.42$ versus .51$)$, suggesting that hospital RNs have higher firm labor supply elasticities than do the college-educated female control group. Table 2 also provides CPS measures of $M$ for all women and men, and women and men classified by low and high education (low is high school or below). Not only is $M$ for hospital RNs lower than among the control group, it is substantially lower than the .58 value among all women and for each female schooling group. The calculated $M$ for RNs is also lower than among all men (.42 versus .47), being far below the .52 value for less-educated men and similar to the .40 value for highly $\mathrm{n}$ educated men. These comparisons are suggestive. First, new monopsony is more likely to affect low-skill than high-skill workers and women more than men, points made previously by Manning (2003). Second, whatever one thinks of new monopsony, the mobility of hospital RNs across jobs makes them a questionable candidate for a prototypical worker group harmed by employer power.

\subsection{Tests for classic monopsony}

In this section, we examine the relationship of relative $\mathrm{RN}$ wages with measures of classic monopsony-labor market size and employer concentration. Table 3 displays results from the second-step WLS equation for 1998-2002. Shown are coefficients on the Herfindahl index (using, alternatively, hospitals and hospital systems as the employer measure), market 
Table 3

Relative RN wage effects from classic and new monopsony

\begin{tabular}{|c|c|c|c|c|}
\hline & All markets & & CMSA/MSAs & \\
\hline \multicolumn{5}{|l|}{ Hospital concentration } \\
\hline Herfindahl HI & $-.021(.061)$ & - & $.070(.080)$ & - \\
\hline System Herfindahl HI & - & $.001(.056)$ & - & $.089(.074)$ \\
\hline \multicolumn{5}{|l|}{ Market size } \\
\hline Non-urban state groups & - & - & - & - \\
\hline Metro $100-200 \mathrm{~K}$ & $-.009(.041)$ & $-.018(.041)$ & - & - \\
\hline Metro $200-300 \mathrm{~K}$ & $-.035(.035)$ & $-.042(.034)$ & $-.026(.038)$ & $-.023(.038)$ \\
\hline Metro 300-500K & $-.050(.029)$ & $-.054(.029)$ & $-.019(.039)$ & $-.013(.039)$ \\
\hline Metro $500 \mathrm{~K}-1 \mathrm{M}$ & $-.060(.028)$ & $-.061(.029)$ & $-.022(.045)$ & $-.016(.043)$ \\
\hline Metro 1-2M & $-.095(.030)$ & $-.094(.030)$ & $-.049(.049)$ & $-.044(.045)$ \\
\hline Metro 2-5M & $-.088(.036)$ & $-.085(.035)$ & $-.038(.057)$ & $-.031(.052)$ \\
\hline Metro $5 \mathrm{M}$ and over & $-.157(.040)$ & $-.154(.039)$ & $-.111(.060)$ & $-.101(.057)$ \\
\hline \multicolumn{5}{|l|}{ New monopsony } \\
\hline$M^{\mathrm{RN}}$ & $-.037(.050)$ & $-.035(.050)$ & $-.041(.055)$ & $-.034(.056)$ \\
\hline$M^{\mathrm{C}}$ & $.061(.096)$ & $.062(.096)$ & $.092(.109)$ & $.086(.108)$ \\
\hline Sample size & 240 & 240 & 191 & 191 \\
\hline
\end{tabular}

Shown are second step WLS results for the 1998-2002 period, where the dependent variable is the first-step estimate of the RN-to-control group wage by area, with the inverse of first-step standard errors as weights. The first two columns include all markets, while the second two columns exclude the non-urban state areas. Second-step regressions also include labor market means of the first-step variables.

size dummies and the new monopsony measure $M$ (discussed in the next section). Results are shown with and without inclusion of the 49 non-urban state areas.

The coefficients $\psi_{s}$ measure the estimated wage for RNs relative to the control group in each market size category. Classic monopsony predicts that $\psi_{s}$ increase with respect to size. No such result is found. If anything, the RN/control group wage declines as size increases, relative nursing wages being around .09 log points lower in cities of 1-2 and 2-5 million than in non-urban state areas. The comparable figure for the largest metropolitan areas is about $.15 \log$ points. $^{21}$

It is not clear what explains lower relative wages for RNs in large cities. ${ }^{22}$ One possibility is that it reflects relative homogeneity in (unmeasured) nursing quality across markets, coupled with increasing quality by city size among the control group. Based on prior literature (Glaeser and Maré, 2001; Rauch, 1993), we doubt that such a pattern of unobserved quality is strong. The opposite conjecture would hold that there is relative homogeneity in the control group work force, with unmeasured nursing quality decreasing with city size. We cannot dismiss such suggestions out of hand, but would like to see evidence. A second type of explanation focuses on the demand side. If large-city hospitals are more financially

\footnotetext{
${ }^{21}$ City size results are highly similar absent control for hospital concentration (these results not shown).

22 Both RN and control group wages rise with city size, but the former by less than the latter. Theory predicts that utility for equally skilled workers is equivalent (at the margin) across labor markets. Wages do not rise fully with cost of living, however, since area amenities (good climate, etc.) increase land prices and decrease wages, all else the same. DuMond et al. (1999) find that wages increase roughly half as fast as measured cost-of-living across U.S. urban areas.
} 


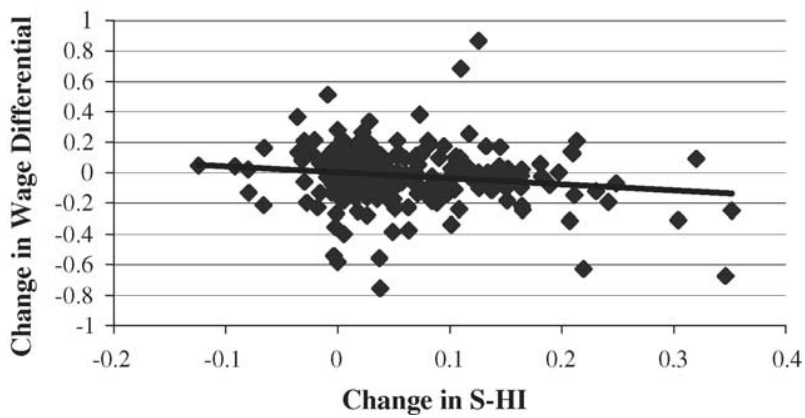

Fig. 3. Changes in area wages and the system Herfindahl index. Shown on the vertical axis are changes in normalized RN/control group log wage differentials between the 1993-1997 and 1998-2002 periods. Shown on the horizontal axis are changes in the system Herfindahl concentration index, $\Delta$ S-HI, between 1993 and 2000.

constrained than in other markets, we might expect to see lower wages, higher turnover, and more vacancies in large-city hospitals. Whatever the explanation, the pattern seen is opposite of that predicted by classic monopsony.

The most direct test of classic monopsony is to estimate the relationship between relative nursing wages and employer concentration, holding market size constant. Estimates of $\theta$,

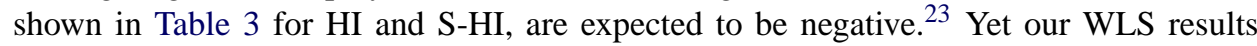
produce estimates of $\theta$ that are effectively zero for the full sample and weakly positive for the urban sample. Little difference is found between the HI and S-HI measures. Similar qualitative results are found for 1993-1997 (see Hirsch and Schumacher, 2004a).

In short, it is difficult to find wage level evidence supporting the presence of classic monopsony in nursing labor markets for the long run. However, we find suggestive evidence that competition affects short-run wage adjustments. Fig. 3 shows the simple correlation between market changes in $\mathrm{RN}$ relative wages $(\Delta \varphi)$ and system $\mathrm{HI}(\Delta \mathrm{S}-\mathrm{HI})$. There appears to be a small inverse relationship, suggesting that relative wages fall when hospitals become more concentrated. The top panel of Table 4 presents estimates from Eq. (4), which regresses the change in relative RN/control group wages between 1993-1997 and 1998-2002 on changes in the Herfindahl index, along with other covariates. Here, we find evidence consistent with monopsonistic employer power. Coefficients on $\Delta \mathrm{S}-\mathrm{HI}$ are negative, significant, and robust to alternative specifications, indicating that hospital system consolidation during the 1990s was associated with slower RN wage growth. The coefficient on $\Delta \mathrm{S}-\mathrm{HI}$ is about -.40 , implying a change in concentration of .05 (roughly the change in means, as seen in Table 1) is associated with a $.02 \log$ point (about $2 \%$ ) relative RN wage decrease. This is not a huge effect, nor is it trivial. For the quartile of labor markets with the largest increase in S-HI (compared to the lowest), the relative RN wage decreases by $.034 \log$ points (not shown). Using the hospital-based measure of $\Delta \mathrm{HI}$ (these results not shown), estimates are about half the size of those seen in Table 3, consistent with wage setting taking place more at the system than individual hospital level.

\footnotetext{
23 A positive coefficient would be consistent with rent sharing if hospitals facing less product market competition were both able and willing to pay higher relative wages.
} 
Table 4

The effect of changes in hospital system concentration on RN wage, employment, and staffing changes, 1993-1997 to $1998-2002$

\begin{tabular}{lcc}
\hline & All markets & CMSA/MSAs \\
\hline System Herfindahl coefficients from log wage change equations & \\
1. Base specification & $-.370(.157)$ & $-.418(.174)$ \\
2. 1 plus change in hospital census & $-.366(.157)$ & $-.417(.174)$ \\
3. 1 plus \%HMO & - & $-.401(.174)$ \\
System Herfindahl coefficients from log employment change equations & \\
1. Base specification & $-.133(.204)$ & $-.037(.193)$ \\
2. 1 plus change in hospital census & $-.093(.175)$ & $-.054(.168)$ \\
3. 1 plus \%HMO & - & $-.039(.193)$ \\
System Herfindahl coefficients from staffing change equations & \\
1. Base specification & $-.568(.207)$ & $-.543(.221)$ \\
2. 1 plus change in hospital census & $-.589(.200)$ & $-.530(.209)$ \\
3. 1 plus \%HMO & - & $-.546(.221)$ \\
$N$ & 240 & 191 \\
\hline
\end{tabular}

Sample consists of $191 \mathrm{CMSA} / \mathrm{MSAs}$ and 49 non-urban state groups. Shown are coefficients on $\Delta$ S-HI (the 1993-2000 change in hospital system concentration). The dependent variable in the top panel is the change in the relative RN wage. In the middle panel the dependent variable is the change in log RN employment and in the bottom panel the dependent variable is the change in the staffing ratio for the market. The base specification for each equation includes the change in market average level of the following characteristics: degree type, experience and experience squared, union status, race and ethnicity, part-time, gender, public employment, martial status, and the change in the state unemployment rate. Also included are size dummies.

Employer concentration appears to impact relative wages, at least in the short run. Less certain is whether this relationship really reflects changes in employer power or instead results, say, from market-wide shifts in labor demand. It is plausible that wage decreases in markets with hospital consolidation simply reflect a decline in patient and RN demand. However, when we include a variable measuring change in the log of the hospital census (or in work not shown, employment), the coefficient on $\Delta \mathrm{S}-\mathrm{HI}$ is affected little. Likewise, the estimated coefficient on $\Delta \mathrm{S}-\mathrm{HI}$ is unaffected when we include a measure of HMO penetration (for the subset of markets for which it was available). ${ }^{24}$ In the middle panel of Table 4, we provide estimates from employment change equations, since the classic monopsony model predicts lower wages and employment. Employment growth appears unaffected by changes in hospital concentration.

Our interpretation of the longitudinal evidence is that modest RN wage changes have occurred in response to changes in hospital concentration, consistent with classic monopsony in the short run. It is not clear whether this represents evidence for long-run monopsony. Those who distrust the previous wage level results owing to possible omitted variables may choose to emphasize the wage change results and conclude that monopsonistic wage effects are found in RN labor markets over the long run. Our preference, however, is not to reject

\footnotetext{
24 The $\Delta$ S - HI coefficient was unaffected as well by the addition of an HMO change variable, but its noise-tosignal ratio is high. We thank Laurence Baker for providing the HMO data (see Baker, 1995; Baker and Phibbs, 2002).
} 
the wage level results, given the high mobility of RNs across employers and our inability to think of an omitted fixed effect likely to erase evidence of monopsony in the wage level analysis. ${ }^{25}$ Our interpretation is that the absence of monopsonisitic evidence in wage level equations for multiple time periods is likely to indicate that there is sufficient RN mobility within and across labor markets so that short-run wage differentials associated with market structure are not sustained in the long run.

\subsection{Monopsony power, staffing, and effort}

Currie et al. (2005) extend the classic monopsony model to allow employers to set not only wages and employment, but also "effort" via staffing levels. Rather than leading to lower wages, monopsony may instead lead to lower staffing and higher required effort, lowering worker utility just as would lower wages. Lower staffing decreases RN satisfaction owing to greater demands on their time and a poorer quality of patient care. The authors examine California nursing data over the 1989-1999 period, treating takeovers by hospitals chains as increases in product and labor market concentration. They find that RNs see few declines in wages following takeovers, but realize increases in the number of patients per nurse. They find increases in employment, however, and conclude that their results are more consistent with a contracting model than with monopsony or the standard competitive model.

In work not shown (see Hirsch and Schumacher, 2004a), we examine whether monoponistic power in nursing markets is associated with higher required work effort, as measured by the staffing ratio of RNs to patients, designated $S$ (the same measure in Currie et al., 2005). Little if any relationship of $S$ with respect to market size, S-HI or $M^{\mathrm{RN}}$ is found. Although no cross-sectional relationships between staffing and measures of classic monopsony are found, a negative relationship is seen between changes in the system Herfindahl index and in $S$ between 1993 and 2000 (Table 4, bottom panel). Staffing falls (i.e., effort rises) following hospital system consolidation. These results comport well with evidence found by Currie et al. (2005) of decreased staffing following California hospital mergers. Our interpretation of this relationship is similar to that given to the wage change results-changes in staffing are likely to reflect short-run responses to market structure changes, but are unlikely to survive in the long run. Others might prefer to discount the staffing level analysis due to omitted fixed effects, instead placing emphasis on the staffing change estimates. ${ }^{26}$

\subsection{Tests for new monopsony}

Table 3 presents second-step WLS results relating the relative RN wage to $M^{\mathrm{RN}}$, the proportion of hospital RN new hires from outside $\mathrm{RN}$ employment, and $M^{\mathrm{C}}$, the proportion

\footnotetext{
25 As stated, we know of no omitted wage determinant driving the wage level coefficient on HI to zero. Such a variable must be correlated with RN wages and $\mathrm{HI}$ in opposite directions, but not strongly correlated with other covariates.

26 State laws or collective bargaining agreements can constrain adjustments in RN employment through mandated minimum staffing ratios. For discussion of the expected effects from staffing requirements adopted in California, see Spetz (2001). Federal legislation introduced in Congress is described in American Nursing Association (2003).
} 
Table 5

New monopsony wage effects by education level

\begin{tabular}{llll}
\hline & All & High school or less & Some college or more \\
\hline Women & $-.161(.101)$ & $-.180(.077)$ & $-.044(.087)$ \\
$N$ & 266,660 & 106,916 & 159,744 \\
Men & $-.059(.096)$ & $-.030(.086)$ & $-.003(.065)$ \\
$N$ & 267,362 & 115,719 & 151,643 \\
\hline
\end{tabular}

Shown are coefficients and "robust" standard errors adjusted for within-market correlation on the monopsony measure $M$, included in separate micro log wage equations by worker group. $M$ is calculated separately by labor market for each group, woman and men, and women and men by education group, using all rotation groups from the 1994-2002 CPS (see Appendix A for details). The wage sample is drawn from the 1998-2002 CPS ORG files. Other variables included in the wage equations are years of schooling, experience and its square, dummies for part-time status, race and ethnicity (3), marital status (2), union status, public employment, year (4), region (8), market size (7), and the state level unemployment rate by year.

of new hires from outside employment among the college-educated female control group. The new monopsony literature predicts that each group's wages are negatively related to their respective $M$. No significant relationship is found, although the estimate of $\zeta$ (the coefficient on $M^{\mathrm{RN}}$ ) is negative. A value of $\zeta=-.04$ implies that a .20 difference across markets in $M^{\mathrm{RN}}$ is associated with a less than $1 \%(.008 \log$ point) difference in the RN wage. More substantial (but insignificant) is the expected positive coefficient on $M^{\mathrm{C}}$. In short, we observe higher relative RN wages where control group wages are negatively affected by high values of $M^{\mathrm{C}}$ outside the RN labor market (for further evidence, see Hirsch and Schumacher, 2004a). A limitation of our analysis is that we are unable to provide longitudinal estimates, absent reliable measures of $\Delta M$.

Given the novelty of our test for new monopsony, we also examine the relationship between the new monopsony measure $M$ and the wages of workers throughout the labor market. In Table 5, we present micro wage regression results for the period 1998-2002 among non-student women and men, ages 20-64, classified by low and high education. Values of $M$ across our 240 labor markets are calculated by gender and education using the monthly CPS for the 1994-2002. The results reveal a negative effect of $M$ on the wages of women, but this effect is concentrated among women with little education. In the regression run separately for the low education group, the coefficient on $M$ is -.180 . A change in $M$ from, say, .5 to .6 (roughly a one standard deviation change and the difference between women with high and low education) is associated with about $2 \%$ lower wages. Thus, for less-educated women, for whom values of $M$ are relatively high, monopsonistic employer power has a modest impact on wages. ${ }^{27}$ Results for men also produce negative coefficients on $M$, but these are close to zero (and insignificant).

Whatever one thinks of new monopsony, its impact in nursing markets is minimal. This conclusion is based first on evidence of little if any relationship between RN wages and $M$ and, second, on the fact that RN new hires are more likely to have moved across employers

\footnotetext{
${ }^{27}$ It is reasonable to ask if the relationship for less-educated women reflects monopsonistic power or if $M$ is instead a proxy for some other wage determinant. One possibility is that workers with low unmeasured skill have higher job turnover, producing high values of $M$. Observed wages may reflect these low skills and not employer power.
} 
than are new hires outside of nursing. The finding that nurses are more mobile and less affected by employer power than workers elsewhere should not be surprising. Few of the skills acquired by RNs in school and on the job are hospital specific. Information barriers typical in markets with heterogenous employers seem unlikely among hospital RNs. Firmspecific attachment for other reasons seems no more likely for hospital RNs than for workers elsewhere. We do not dispute that labor supply curves facing firms (hospitals) are upward sloping-we do not accept that this is sufficient to conclude that there exist low wage outcomes and the exercise of employer power.

\section{Conclusion}

Nursing is frequently proffered as an example of a monopsonistic labor market. This paper attempts to reconcile what has been rather mixed evidence on the topic. RNs and a control group of college-educated women are segmented into 240 urban and non-urban labor markets over the periods 1993-1997 and 1998-2002. Evidence consistent with classic monopsony is found using longitudinal analysis between the two periods, increases in hospital system concentration being associated with moderately lower RN wage growth and staffing ratios. Using wage level analysis, however, no evidence is found for higher relative nursing wages or staffing in larger markets or in markets with lower hospital concentration. For reasons stated earlier, our preferred interpretation is that the wage level analysis is likely to measure long-run outcomes. We conclude that short-run effects on wages and staffing from classic monopsony are unlikely to be sustained over time. Readers concerned that wage level results might be biased (toward zero) due to omitted fixed effects, however, might reasonably conclude that the longitudinal results reflect the long-run as well as shortrun effects of classic monopsony.

Little or no relationship is found across labor markets between RN wages and $M$, a mobility measure offered in the new monopsony literature as a proxy for the inverse supply elasticity. Values of $M$ are substantially lower for hospital RNs than for women (or men) economy-wide, reflecting nursing skills that are readily transferable and the presence of multiple hospital and non-hospital employment options for RNs. We find a weak negative relationship between wages and $M$ for the college-educated female control group, and a more substantial negative relationship between $M$ and the wages of less-educated female workers. Because of data limitations, we were unable to provide longitudinal analysis relating wage changes to changes in $M$.

Two principal conclusions follow from our analysis. First, evidence of upward sloping labor supply is not sufficient to infer monopsonistic outcomes. We do not dispute that workers are often immobile over the short and medium runs and that employers face upward sloping labor supply. It does not follow that differences in supply elasticities necessarily generate differences in wages. Before concluding that monopsony is important, one should measure outcomes. Second, whatever one thinks about the importance of monopsony, classic or new, the market for hospital RNs is a questionable example given the relatively high mobility of RNs across employers. Absent more compelling evidence of monopsonistic outcomes in nursing labor markets, economists should look elsewhere for a prototypical example of monopsony. 


\section{Acknowledgements}

We thank Alexis Arel and Wendy Dyer for expert assistance with the AHA data; Ted Frech, Darren Grant, Deborah Haas-Wilson, Daniel Rees, Joanne Spetz, Jennifer Troyer, and the editor and referees for helpful suggestions on earlier drafts; and session participants at meetings of the International Health Economics Association, Society of Labor Economists, and Southern Economic Association for their input.

\section{Appendix A. Calculating new monopsony measures from the CPS}

A new monoposony measure, $M$, is compiled for various groups (see Table 2) from all rotation groups of the Current Population Survey (CPS) for 1994-2002. As seen in Eq. (2) of the text, $M$ is equal to the proportion of new hires from outside employment $(u+n)$ rather than other employers $(e)$. Households are in the CPS for four consecutive months (rotation groups 1-4), out for 8 months, and then in the same 4 months the following year (rotation groups 5-8). Beginning in 1994, individuals employed in the previous month are asked if in their primary job they have the same employer as in the previous month (variable PUIODP1). This question is asked of rotation groups $2-4$ and $6-8$, but not 1 and 5 . To calculate $M$, we begin with currently employed wage and salary workers, ages 20-64 (we exclude full-time students). We reach back to the previous month and record (among other things) if they were employed, unemployed, or out of the labor force. This large group is then restricted to the small subset who are new hires or recruits-those currently employed who state they have a different employer than in the prior month or during the prior month were either unemployed or out of the labor force. Using this information, $M$ is calculated using CPS employment weights. Households that move between months fall out of the CPS, as do individuals who change households. By restricting samples to those currently employed as RNs in hospitals or who are wage and salary women within certain occupation and education groups, we construct the measures $M^{\mathrm{RN}-\mathrm{CPS}}$ (nationwide), and $M^{\mathrm{C}}$ (nationwide and by labor market).

\section{References}

Adamache, K.W., Sloan, F.A., 1982. Unions and hospitals: some unresolved issues. Journal of Health Economics $1(1), 81-108$.

American Hospital Association, 1994. Hospital Statistics (Data Compiled from the 1993 Annual Survey of Hospitals). Chicago.

American Hospital Association, 2002. Hospital Statistics (Data Compiled from the 2000 Annual Survey of Hospitals). Chicago.

American Nursing Association. ANA Applauds Nurse Staffing Bill Introduced in U.S. House of Representatives. Press Release, December 11, 2003. http://www.tnaonline.org/ANAstaffbill.pdf.

Baker, L.C., 1995. County-Level Measures of HMO Enrollment and Market Share. Department of Health Research and Policy, Stanford University, Mimeo.

Baker, L.C., Phibbs, C.S., 2002. Managed care, technology adoption, and health care: the adoption of neonatal intensive care. Rand Journal of Economics 33 (3), 524-548. 
Baker, M., Fortin, N.M., 2001. Occupational gender composition and wages in Canada: 1987-1988. Canadian Journal of Economics 34 (2), 345-376.

Bhaskar, V., Manning, A., To, T., 2002. Oligopsony and monopsonistic competition in labor markets. Journal of Economic Perspectives 16 (2), 155-174.

Boal, W.M., Ransom, M.R., 1997. Monopsony in the labor market. Journal of Economic Literature 35 (1), $86-112$.

Buerhaus, P.I., Staiger, D.O., Auerbach, D.I., 2004. New Signs of a Strengthening U.S. Nurse Labor Market? Health Affairs Web Exclusive, 23 (Supp. 2), pp. 526-533.

Burdett, K., Mortenson, D.T., 1998. Wage differentials, employer size, and unemployment. International Economic Review 39 (2), 257-273.

Cuellar, A.E., Gertler, P.J., 2004. How the expansion of hospital systems has affected consumers. Heath Affairs 24 (1), 213-219.

Currie, J., Farsi, M., MacLeod, W.B., 2005. Cut to the bone? Hospital takeovers and nurse employment contracts. Industrial and Labor Relations Review 58 (3), 471-493.

Dranove, D., Ludwick, R., 1999. Competition and pricing by nonprofit hospitals: a reassessment of Lynk's analysis. Journal of Health Economics 18 (1), 87-98.

DuMond, J.M., Hirsch, B.T., Macpherson, D.A., 1999. Earnings differentials across labor markets and workers: does cost of living matter? Economic Inquiry 37 (4), 577-598.

Fong, T., March 3, 2003. Consolidation squabble. Modern Healthcare 33 (9), 7.

Gaynor, M., Vogt, W.B., 2003. Competition Among Hospitals. Rand Journal of Economics 34 (4), 764-785.

Gaynor, M., Hass-Wilson, D., 1999. Change, consolidation, and competition in health care markets. Journal of Economic Perspectives 13 (1), 141-164.

Glaeser, E.L., Maré, D.C., 2001. Cities and skills. Journal of Labor Economics 19 (2), 316-342.

Hirsch, B.T., Schumacher, E.J., 1995. Monopsony power and relative wages in the labor market for nurses. Journal of Health Economics 14 (4), 443-476.

Hirsch B.T., Schumacher, E.J., 2004a. Classic monopsony or new monopsony? Searching for evidence in nursing labor markets. IZA Discussion Paper No. 1154.

Hirsch, B.T., Schumacher, E.J., 2004b. Match bias in wage gap estimates due to earnings imputation. Journal of Labor Economics 22 (3), 689-722.

Lynk, W.J., 1995. Nonprofit hospital mergers and the exercise of market power. Journal of Law and Economics 38 (2), 437-461.

Manning, A., 2003. Monopsony in Motion: Imperfect Competition in Labor Markets. Princeton University Press, Princeton, NJ.

Melnick, G., Keeler, E.B., Zwanziger, J., 1999. Market power and hospital pricing: are nonprofits different? Health Affairs 18 (3), 167-173.

Mortensen, D.T., 2003. Wage Dispersion: Why Are Similar Workers Paid Differently? MIT Press, Cambridge, MA.

Rauch, J.E., 1993. Productivity gains from geographical concentration of human capital: evidence from the cities. Journal of Urban Economics 34 (3), 380-400.

Saxonhouse, G.R., 1976. Estimated parameters as dependent variable. American Economic Review 66 (1), $178-183$.

Schumacher, E.J., 1997. Relative wages and the returns to education in the labor market for registered nurses. In: Polachek, S. (Ed.), Research in Labor Economics, vol. 16, pp. 149-176.

Smith, C., Cowan, C., Sensenig, A., Catlin, A., 2005. Trends: health care spending growth slows in 2003. Health Affairs 24 (1), 185-194.

Spetz, J., 2001. What should we expect from California's minimum staffing legislation? Journal of Nursing Administration 31 (3), 132-140.

Staiger, D., Spetz, J., Phibbs, C., 1999. Is there Monopsony in the Labor Market? Evidence From a Natural Experiment. National Bureau of Economic Research Working Paper No. 7258.

Sullivan, D., 1989. Monopsony power in the market for nurses. Journal of Law and Economics 32 (2 (pt. 2)), S135-S178.

Taylor, M., 2003. Getting back in the game. Modern Healthcare 33 (7), 26-28, 30-31, 34. 